\title{
Stakeholder Perceptions of Intervention Strategies to Improve the Practice of Extra Lessons in Zimbabwean Urban Day High Densi- ty Secondary Schools
}

\author{
Richard Bukaliya ${ }^{1 *}$, Florence Jura ${ }^{2}$

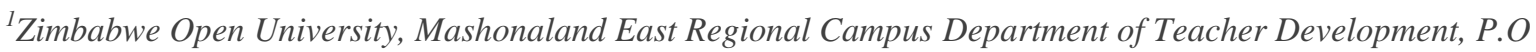 \\ BOX 758 Marondera, Zimbabwe \\ ${ }^{2}$ Zimbabwe Open University, Student Management Unit, Harare Chitungwiza Regional Campus, P.O. BOX \\ MP1119 Mount Pleasant, Harare, Zimbabwe \\ *Corresponding Author: Richard Bukaliya, Zimbabwe Open University, Mashonaland East Regional \\ Campus Department of Teacher Development, P.O BOX 758 Marondera, Zimbabwe
}

\begin{abstract}
The study was interpretivist in nature and adopted the qualitative approach to data generation and interpretation. The case study was a multiple one with the selection of three schools in Chegutu urban, Zimbabwe. In-depth interviews with teachers and School Inspectors, focus group discussions with learners were adopted for data generation. Twenty-three participants made it into the study sample. The researcher utilised the critical case sampling to select a small section of important cases from a group of prospective cases. These selected cases yielded the most important information that had the greatest impact on the development of knowledge being sought by the researcher, in this case, issues on strategies to do with the improvement of extra lessons. The 23 participants from where data were generated consisted of 8 teachers, 6 learners, 6 parents and 3 school inspectors who were sampled through non-probability purposive sample. The study participants were asked to proffer suggestions for the improvement of the practice of extra lessons to the satisfaction of all stakeholders. Stakeholders in this regard included teachers and their associations, learners, parents and the Ministry of Primary and Secondary Education (MOPSE). From the findings policy areas for improving the practice of extra lessons in secondary schools included the registration of service providers, offering extra lessons during formal learning hours and barring teachers from offering extra lessons to learners they teach in the formal schools. Some effective strategies suggested by participants included the introduction of on-line tutoring. There was also need for support from all sectors and stakeholders. The study came up with the On-Off Model of extra lessons implementation which could be incorporated into the education system for use to enhance the desirability of extra lessons by all concerned stakeholders.
\end{abstract}

Keywords: stakeholder perceptions, intervention strategies, extra lessons, secondary schools

\section{INTRODUCTION}

In the quest for high quality education, there has been an escalation of desire among parents and guardians looking for alternative space meant to propel children academic achievement (Bray, 2011). Some of the alternative measure at the parents ' disposal have been to enroll their children in the much resourced private and independent schools, or alternatively enroll them in the cheaper schools but expose them to extra lessons. Due to their potency to improve academic achievement of learners, among other benefits, extra lessons have become very popular, globally. Even most modern societies with well pronounced formal education systems have adopted the extra lessons. For example, East Asia, for example, South Korean learners have enrolled in Hankwon, a term referring to cram schools, at a wider scale (Lee \& Shouse, 2011). In North America, according to Davies (2014), in Canada, there has been a rising desire for extra lessons. In Africa, in Egypt, extra lessons were the thriving activity, termed privates or durus Khususiyya, (Hartmann, 2008).

In Zimbabwe, extra lessons were initially aimed to assist learners lagging in some aspects of their formal schooling. According to Tokwe (2010), extra lessons in the Zimbabwean education system were meant to be remediation platform which was negotiated by parents with reputable educators who would assist children experiencing learning complications in particular learning areas. Several reasons have proffered for the engagement in extra lessons. Teachers, on one hand, have used extra lessons to 
argument their meagre salaries and have also voiced concern that there is inadequate learning time in the formal school. Added to that, the addition of more learning areas, such as Physical Education and Sport, HIV and AIDS Education, Health and Life skills and Guidance and Counselling, has given rise to the extra lessons (Munikwa \& Mutungwe, 2011; Tokwe, 2010), into the already congested school curriculum has made the situation more problematic. Parents have seen it fit to send their children for the extra tuition so that they pass their examinations. The practice has, therefore, become so intense that stakeholders have started to debate on what role these initiatives may be playing in the mainstream Zimbabwean education system (Munikwa \& Mutungwe, 2011; Tokwe, 2010).

While some spheres of the Zimbabwean society, for example, teachers and learners, have advocated for and have been involved in the extra lessons, others such as the government, through MOPSE, have expressed grave reservations against the practice (Munikwa \& Mutungwe, 2011; Tokwe, 2010). MOPSE raised concern that extra lessons came with a cost for the already burdened parents (Jinga \& Ganga, 2012). Indeed, some parents and MOPSE have gone to an extent of labelling the extra lessons unscrupulous and corrupt activities that are aimed at the enrichment of the teachers salaries considering meager remuneration being offered by the Public Service Commission (PSC), which is the employer in Zimbabwe, of all the public sector workers, including teachers (Bewu, 2013).

\section{Statement Of The Problem}

Literature on the strategies to improve the practice of extra lessons is bountiful. However, there appears arguments as to how these strategies are effective in the improvement of the practice. Some of the strategies have been questioned while others have been well received in some settings. This study, therefore, seeks to establish stakeholders' perceptions of intervention strategies to improve the practice of extra lessons in Zimbabwean Urban Day High Density Secondary Schools.

\section{RESEARCH QUESTIONS}

The study was guided by the following research questions:

1. Which policies can be tailor made to improve the practice in secondary schools?

2. How beneficial is stakeholder involvement in the improvement of the practice?

3. What model can be best applicable for offering extra lessons to secondary school learners?

\section{LITERATURE REVIEW}

Studies by Shrake (2010), Budeiene and Zabulionis (2016), Bray and Lykins (2012) and Bray (2011), among others, have provided views on how best extra lessons can be handled.

Shrake (2010), for example, advocates the setting up of tutoring agencies. To that effect, it would require the enactment of policies that regulate the formation and operation of such agencies. Policy makers should be seized with the conceptualising such policies. In the same vein, Bray (2011) suggests that individual teachers could be allowed to operate as service providers as well join agencies and work as groups to provide extra lessons. Through such registered entities, governments can be able to generate the much-needed revenue into the national fiscas through taxation of individuals or the agencies. The Government of Zimbabwe can also benefit from this arrangement, but Bray (2011) cautions that there is need for a regulatory framework to operationalise the execution of the extra lessons.

Bray and Lykins (2012) advance the view that private tutoring could be supported through state funding as is the case in England. The Making Good Progress initiative, in England, makes sure that resources are available for teachers involved in one-on-one tutoring. Another initiative was launched in France where parents paying for extra lessons for their children were eligible for a 50\% tax claim refund from government.

According to a report by Bray (2011), to the European Commission, informal tutoring could be problematic to regulate although teachers on government pay roll could be regulated in way or the other. Where learners and their parents seek the extra lessons from self-employed tutors, regulation is a problem as they arrange the teaching and learning outside the auspices of the government initiatives. However, Bray (2011) is of the opinion that teachers should be prohibited from offering extra lessons that are purely exclusive of government initiated programmes. 
Budiene and Zabulionis (2016) state that in Lithuania, the government introduced freelance teaching where qualified teachers provide extra lessons to learners whom they do not teach in the mainstream education system. The teachers provide strictly non-formal education that supplements the mainstream curriculum. Such teachers have the right to work according to their own programmes if they do not infringe the laws of their mainstream employment. From a Zimbabwean perspective, licensing freelance teacher could be prone to abuse. Teachers can connive and swap learners as the law prohibits them only from extra lessons for learners, they teacher in the mainstream.

Bray and Lykins (2012) argue that because examination results are the main selection criterion for admission into educational institutions at most levels, there is need for the reformation of assessment systems. First, there is need to review the curriculum of these institutions and, according to Bray and Lykins (2012), this has been effective in most Asian countries as it helps reduce the desire for private tutoring significantly, thus curbing the practice. Secondly, assessment procedures need to be revisited to incorporate continuous assessment, thus reducing the anxiety that goes with the need to pass terminal examinations. This probably could help in the reduction of fear of examinations as the final grade shall be arrived at by encompassing results from formative assessment procedures (MOPSE, 2017).

\section{RESEARCH METHODOLOGY}

The study was interpretivist in nature and adopted the qualitative approach to data generation and interpretation. It was aimed at understanding stakeholders` perceptions of the best strategies to adopt in implementing extra lessons. Thus, it was based on building a complex, holistic picture, formed with words, reporting detailed views of informants, and conducted in a natural setting, in this case, the schools (Creswell, 2012; Flick, 2011). The case study design was used to gain a greater depth of information on the strategies to adopt for extra lessons to be successfully implemented in secondary schools. In-depth interviews with teachers and School Inspectors, focus group discussions with learners were adopted for data generation, resulting in narrative and descriptive accounts of what participants perceived as best practices. The case study was a multiple one with the selection of three schools in Chegutu urban, Zimbabwe. The multiple sites, data generation instruments and multiple types of participants enabled the triangulation of data in which comparisons were made possible. (Creswell, 2012).

\section{RESEARCH PARTICIPANTS}

Twenty-three participants made it into the study sample. The 23 participants from where data were generated consisted of 8 teachers, 6 learners, 6 parents and 3 school inspectors who were sampled through non-probability purposive sample. The researcher utilised the critical case sampling to select a small section of important cases from a group of prospective cases. These selected cases yielded the most important information that had the greatest impact on the development of knowledge being sought by the researcher, in this case, issues on strategies to do with the improvement of extra lessons (Patton, 2014). The researcher identified the critical cases of participants that were taking part in extra lessons. Their level of participation and experience in the phenomenon was very critical to inform conclusions and make logical generalisations in the study (Johnson \& Christensen, 2012). Participants` identities were hidden for purposes of anonymity and confidentiality using pseudonyms, as well as codes. Teachers were coded T1 to T6. Learners were coded L1 to L6 and parents P1 to P6, whereas school inspectors were coded S1 to S3. This assisted in attributing responses attached to the different participants at the same time persevering their anonymity.

\section{Presentation And Discussion Of Findings}

The study participants were asked to proffer suggestions for the improvement of the practice of extra lessons to the satisfaction of all stakeholders. Stakeholders in this regard included teachers and their associations, learners, parents and the Ministry of Primary and Secondary Education (MOPSE). There was need to come up with such strategies because not all stakeholders agreed as to whether the extra lessons were playing a positive role or not, in the schools. Parents were not in agreement and the same went for the different political players. The Minister of Primary and Secondary Education made several pronouncements expressing his displeasure of extra lessons and to the effect that extra lessons the ministry went on to ban them and yet some Members of Parliament and councilors were in favour of the extra lessons. 


\subsection{Policy Areas for Improving the Practice of Extra Lessons in Secondary Schools}

\section{$>$ Registration of Service Providers}

Stemming from the excerpts is the suggestion by participants that extra lesson providers need to be registered so that they can operate. This is one of the sentiments that came from most of the teacher participants. Out of the 8 participants, $6(75 \%)$ argued that the same method was being used for nurses and other staff in the medical fraternity. For example, Mr. Jonasi from school S3, explained that extra lessons could be regulated by the MOPSE from the perspective of non-formal education, to include backyard lessons provided they are regulated and eventually inspected by the school authorities, just like what is happening in the formal schools. Mr. Jonasi said:

\section{There is need to create time out of normal school hours when learners could attend extra lessons outside of the mainstream, where learners need to be attended to at the same time creating a situation whereby the ministry provides the inspectoral role.}

In Zimbabwe, nurses have been given the leeway to register private nursing homes which have since sprouted in most areas, including the high-density areas. However, from the contributions by the participant, it is very important to note that the issue to do with registration and inspection are very paramount. The same sentiments are echoed by Mr. Tsuro, a teacher school S3, who seemed to be disgruntled by "opportunists who were not actual teachers", but those bent on making money pretending to be offering quality service. He remarked that extra lessons should continue but "we should not have opportunists. Let's ban them and let's promote the teachers who have the children at heart, hence making some provisions for a regulatory framework". From the perspectives, those who tended to abuse learners on the pretext of offering extra lessons could be locked out of the system of registration and eventual inspection. The idea of regulating extra lessons was also advanced by Mr. Tsuro who argued by sharing his opinions saying:
Some of these extra lessons need to be regulated because I have seen the proliferation of quite a good number of opportunists whom I might term bogus teachers or cheaters, so to speak, who are just jumping on board the ship pretending to be offering extra lesson and those one need to be regulated so that we leave real teachers holding extra lessons. We should also reach a compromise with the parents and other stakeholders so that at least no one would be seen to be complaining that the other part is being duped, with us also not complaining that we are being underpaid as we offer these extra lessons. So, I think a compromise should be reached by all stakeholders in the education sector and all those who are concerned by the failure of these children.

The phrase "need to be regulated" and "reach a compromise" go to show the dire need for specific laws that hinder opportunists from offering extra lessons at the same time making sure those that are capable are taken on board to provide quality extra lessons. Through regulation, the system could be made tight such that parents are provided a meaning return out of their investment as currently some are victims to unscrupulous teachers as reflected in "being duped". In line with these findings, Bray (2011) is of the opinion that teachers should be prohibited from offering extra lessons that are purely exclusive of government initiated programmes. However, this regulation could be a problem where extra lessons are carried out clandestinely.

Another aspect of regulation can come in when there is a fixed charge for the extra lessons to be observed by all service providers. Mr. James from school S3, therefore, asserted that a minimal fee that is affordable by all be paid to incentivise all the teachers who take part. Incentivise in this regard could imply just a token of appreciation where teachers are recognised for their extra effort in providing extra lessons, all this coming out of the earlier on alluded to compromise. The findings are in line with those by Budeiene and Zabulionis (2016) in a study in Lithuania where regulations had been put in place for those intending to go private extra lesson. In Lithuania, the government introduced freelance teaching for qualified teachers only on condition that teachers provided extra lessons to learners whom they did not teach in the mainstream education system (Budeiene \& Zabulionis, 2016).

\section{$>$ Streamlining Educational Policies in the Mainstream System}

Participants were of the view that there is need to have a re-look at the policies of the mainstream education system that pave way for the extra lessons. Where there are weaknesses, extra lessons tend 
to mushroom. To counter the existence of extra lessons, policies addressing the weaknesses in the mainstream, that give rise to extra lessons, need to be promulgated and enacted. For example, Mr. James indicates that extra lessons are a result of increased enrolments in the classroom. He states that one teacher is now responsible for more than 60 learners at a time. This is contrary to the dictates of MOPSE in Secretary`s Minute Number 1 of 1987 which stipulates that at secondary school, the teacher-pupil ratio should be 1:32 at O level and 1:40 at ZJC. Mr. James advocates that the teacherpupil ratio be reduced to $1: 30$ or 40 to enable teachers to be able to do their work effectively in the mainstream. Even children would be able to perform better because at times teachers are overwhelmed, overburdened with classes reaching up to 60 learners, as indicated by the participant, to the extent that teachers can no longer offer on one-on-one situations with learners.

\title{
Standardising of the Practice of Extra Lessons
}

Participants also felt the need that there is need to standardise the practice of extra lessons. Mr. Oliver (P3), a parent, advances the suggestion that there should be a standard way of undertaking these extra lessons. He made the following remarks:

\begin{abstract}
Without supervision, it becomes very difficult. So I think if they allow it to take place at school, I think it will be quite ideal rather than allowing it to happen as it is, in a haphazard manner because this time it is very difficult for one to be, if you go into the street there, into the location, if there is no one who will tell you that there is at a house number such and such, some extra lessons are being carried out, it would be very difficult for you to establish that because really, they are carried out in homes and we have discovered that these houses are not ideal for the teaching and learning processes, but his time extra lessons are carried out in those places which are not really conducive. At times there are no proper desks and chairs where these children can write on and time you would find out that some textbooks might not be available.
\end{abstract}

His remarks indicate that there is need for the environment at which extra lessons are carried out to be conducive. This is seen by the remark that "houses are not ideal for the teaching and learning processes". To further indicate the lack of a conducive learning atmosphere, the participant reflects of the type of furniture that is poor when he says, "there are no proper desks and chairs". Instead of carrying out extra lessons in the backyards, or bedrooms or kitchens, as is happening in some of the high density suburbs, teachers should be allowed to make use of the classrooms which are conducive, at the end of the day and this also make supervision easier as it is currently to monitor the teaching and learning process that is done in different uncoordinated ways as shown by the use of the phrase "happen as it is, in a haphazard manner". Some studies, for example, Bray and Lykins (2012), have also highlighted the need for uniformity in the execution of extra lessons.

Mr. Owens, while acknowledging that the extra lessons should not be stopped, feels that reputable and qualified personnel should continue to teach extra lessons but only, registered study centres should provide extra lessons, where fees need to be determined by MOPSE and conditions monitored by government, to the satisfaction of all stakeholders. Mr. Owens suggested as follows:

There is also need for setting up a uniform fees structure because as things stand, the fees are just according to one`s taste. Where for example, one teacher would ask for ask for $\$ 20.00$ per subject, the other would ask for $\$ 30.00$ per subject.

Fees need to be standard as shown in "uniform fees structure". This is because some teachers get to exploit the situation by charging whatever they want. There was, therefore, need for moderation to make sure that the community pays reasonable charges for the extra lessons.

\section{$>$ Offering Extra Lessons During Formal Learning Hours}

Some participants felt that extra lessons should be offered during formal learning hours where learners were found to be idle especially in the hot sitting schools. Such sentiments came from teachers who saw nothing bad about them using the existing school infrastructure for use during the extra lessons. For example, Mr. Sango who teaches at school S2, also suggests that MOPSE should offer teachers the opportunity to offer extra lessons during formal learning hours "as they found out that students sometimes spent many idle hours in the formal education". The same hours could be invested in extra lessons because it is difficult for tutors to find enough hours during the day to offer 
the lessons to students after hours of school. The idea could also make it possible for inspection to be easy as well as reduce cases of abuse which go unreported where extra lessons are carried in teachers` houses or other backyard accommodation. "Idle hours in the formal education" would include those hours that the learners in the hot sitting schools are not formally occupied, hence the hours could be used meaningfully by teachers and learners getting involved in extra lessons. Besides the need to spend many hours idle, extra lessons also become accessible to school inspectors. School inspector Mr. Mhofu is also in support of the idea of having extra lessons carried out the formal school premises. Due to what he perceives as unfavourable environments where extra lessons were held, the school inspector feels that extra lessons should be carried out at the school to protect learners from abuse with the hope, also of "providing effective monitoring" if the extra lessons were undertaken at school level. These feelings resonate well with findings by Mboi and Nyambedha (2013), in Kenya, where extra lessons were carried out in school premises under the watchful eye of the school administration and education officers during school hours when learners were having free time from the normal timetable.

\section{$>$ Barring Teachers from Offering Extra Lessons to Learners They Teach in the Formal Schools}

Prohibiting teachers from offering extra lessons to learners they teach in the formal schools is another strategy coming out of the views by the various participants. According to Ms. Ndumo, teachers who teach learners at the formal school should not take the same learners for extra lessons. She says, "I just think that if people are to have extra lessons it should be from a different teacher so as to get knowledge from other teachers which the other teacher cannot give to the children." From the suggestion, learners will benefit more because they "get knowledge from other teachers which the other teacher cannot give". This is in line with earlier on presented findings that such a situation will help curb corruption by teachers whereby they teach less in the formal school to create demand for extra lessons. However, the same situation can arise where teachers can collude to teach less and exchange learners for extra lessons. The idea to exchange learners can be a better alternative as indicated by most parents who are persistent that teachers from one school should exchange students.

\section{$>$ Introduction of On-Line Tutoring}

On-line tutoring can be another strategy to adopt, advanced by participants, more so in the wake of the COVID-19 pandemic. Mr. Sango recommended that Zimbabwe should incorporate ICTs since the ICT area was booming. There is wide network coverage in the country which could be taken advantage of. According to Mr. Sango, on-line learning could facilitate learning even for distance learning even for adults who are at work since "they can participate in extra lessons even from their smart phones". Accessing the lessons can be made easy due the availability of smart phones. Advantages articulated by teachers on the adoption of on-line extra lessons are that "we can actually reach a broader market share by incorporating such technology". One of the learner participants, L3 indicated that in Zimbabwe, rural school learners that could not access qualified teachers could also be assisted to a large extent by on-line extra lessons. Added to this, L4 indicated that minimising contact between teachers and learners through using ICTs could result in reduced abuse of learners as some teachers could ask "for payment in kind". The same strategy has been advocated by Ventura and Jang (2010) who felt extra lessons could be adopted to reach out more learners in the comfort of their homes thereby avoiding a lot movement. However, with bandwidth and network coverage in Zimbabwe being a challenge, the strategy might not be effective in some areas especially remote areas.

\section{$>$ Need for Support from All Sectors and Stakeholders}

Since extra lessons have been introduced to complement the mainstream system, participants had a feeling that there is need for support from all concerned parties. These include teachers, MOPSE, parents and learners. The views advanced by most participants, banning extra lessons was out of question. Participants would rather have a scenario where, instead of banning the extra lessons, all stakeholders need to support the initiative.

Mr. Tsuro from school S3, notes that learners of today needed more time to grasp concepts hence MOPSE needs to support the teachers. He had this to say: 
I think the MOPSE should also try to support us as we offer these extra lessons considering that the student, we are dealing with now is not self-paced. The students want to be pushed and they want ample material for them to sit for examinations. Most of them are like wheelbarrows who wait for teachers just to continue pushing them. Also, we look at the world that we are now living in; there are now quite several activities that they may partake in as they are idle in the streets. I think extra lessons should be supported. The teachers should offer extra lessons wholeheartedly so that as least every party is satisfied with the service that is offered.

It appears from the excerpt that MOPSE is not providing support for the extra lessons as indicated by "should also try to support us". On one hand, teachers themselves are not performing as expected as shown by "should offer extra lessons wholeheartedly". This shows that they may not be doing it for the need to assist the learners but for their personal economic enrichment. Learners, on the other, are not putting maximum effort into the extra lessons. This is indicated by "most of them are like wheelbarrows who wait for teachers just to continue pushing them". For these reasons there is need for all those involved to put a lot into the extra lessons so that they succeed.

There is, therefore, need to strike a balance so that teachers continue offering extra lessons and getting paid while at the same time students benefit through the extra tuition received. That was why the participant indicated that he was against the idea of banning extra lessons because students who were regarded as rejects, and complete write offs in terms of academic achievement, have been seen to be improving in their marks and even their performance in these schools. The idea of all stakeholders coming to support, particularly government support is echoed by Mr. Zhou from school S2 who said:

So, I believe that there is need for all players to support this initiative of extra lessons so that Zimbabwe will be a better future for everyone. Remember we have learners who feel comfortable when dealing with teachers on a one-on-one basis. So, these people would need to be given chance to attend these extra lessons. So, the government or authorities need to investigate this and then and then just promote these extra lessons because they are important to the learner and they are also important to the teachers.

It seems from the excerpt that the phrase "need for all players to support", the extra lessons, suggests that there are some stakeholders who are not playing their part for the extra lessons to succeed. The Government of Zimbabwe is the main culprit as it is not doing enough to support, and it should come on board and aid as reflected by the phrase "then just promote these extra lessons". Implied in this statement is the view they are not promoting the initiative and going by the ban that they have proclaimed, it shows they are curtailing the efforts of the teachers and parents who feel extra lessons are very important to the learners. In some cases, governments have come in handy to support the extra lessons. For example, Bray and Lykins (2012) advance the view that private tutoring could be supported through funding as the case has been in England through the Making Good Progress initiative where resources were availed for teachers involved in one-on-one tutoring. In France, parents subscribing to extra lessons for their children are eligible for a $50 \%$ tax claim refund from government (Bray \& Lykins, 2012). This goes to demonstrate the support that is provided to teachers and parents despite such support being viewed as perpetuating and exacerbating the inequalities through expanding the rich-poor divide as those who can afford extra lessons are entitled to the tax rebate.

\section{$>$ Legalising Extra Lessons}

Legalising extra lessons is another strategy that could see all stakeholders benefitting from the undertaking, according to the views held by participants. While taking into cognisance the need for appropriate qualifications for the teachers offering extra lessons, there is need for government to operationalise extra lessons through some legal framework. However, according to Mr. Sango, the politicians are skeptical about operationalising extra lessons. He supports the idea when he says, "for the quality of service to be guaranteed, I think it's necessary to license tutors with the qualifications so that there is a level of transparency for both the tutors and the people from the political sphere". A parent participant, Mr. January, whose child attends school at S2, supports the view by Mr. Sango from school S2 and states categorically that extra lessons should not be banned, but there is need for rules and regulations to be put in place for the extra lessons to proceed smoothly. Mr. January, makes the following suggestions: 
Legalising them in some way but not making them a parallel or comparable to private schools. You see there are private schools that registered with the mainstream and then they follow the curriculum though they don't fall under the subdivision of the ministry, but private schools are legalised and follow ups can be done by the ministry. With extra lessons, this is what is done at home, I feel let it be known and by whoever the authorities are that there are there but very little interference, in my view should be done, like say look into how much these teachers charge for those ones and like we want to see the timetable, now that becomes too formal and defeats the whole thing and say we may want some tax from the teacher who is teaching them. This in my view would be ideal.

The aspect of legalisation is the catch word in the excerpt. The participant wants the extra lessons to run parallel with the mainstream just like what is happening with private schools that operate under certain legal instruments. There is need to make sure that whoever is involved is "registered with the mainstream" and officials should not hinder the flow of activities as reflected in "very little interference" as is the case with the operations of private schools. The same view on the legalising of the extra lessons is shared by Mr. Oliver, who suggests that there is need to come up with legislation that regulates how extra lessons could be conducted. Upon coming up with such a policy, the government should then stop targeting teachers and punishing them for carrying out extra lessons. Instead, the government can reap rewards through taxation of those involved in extra lessons as suggested by Mr. January. One of the ideas suggested by Mr. January, coming in because of the legalisation of the extra lessons, is that of that of promoting labour exchange houses, where teachers register and upon call, they are allocated to a learner to whom to provide extra lessons.

This is almost the same view advanced by Bray (2011), for example, when he advocates for the setting up of tutoring agencies. To that effect, it would require the enactment of policies that regulate the formation and operation of such agencies. Policy makers should be seized with the conceptualising such policies. Bray (2011) suggests that individual teachers could be allowed to operate as service providers as well join agencies and work as groups to provide extra lessons. Through such registered entities, governments can be able to generate the much-needed revenue into the national fiscas through taxation of individuals or the agencies. The Government of Zimbabwe can benefit from this arrangement but Bray (2011) cautions that there is need for a regulatory framework to operationalise the execution of the extra lessons.

\section{WAY FORWARD: WHICH STRATEgY TO FOLLOW?}

Having considered the views from the participants and the reviewed literature, the study came up with the On-Off Model of extra lessons implementation. This model could be incorporated into the education system for use to enhance the desirability of extra lessons by all concerned stakeholders.

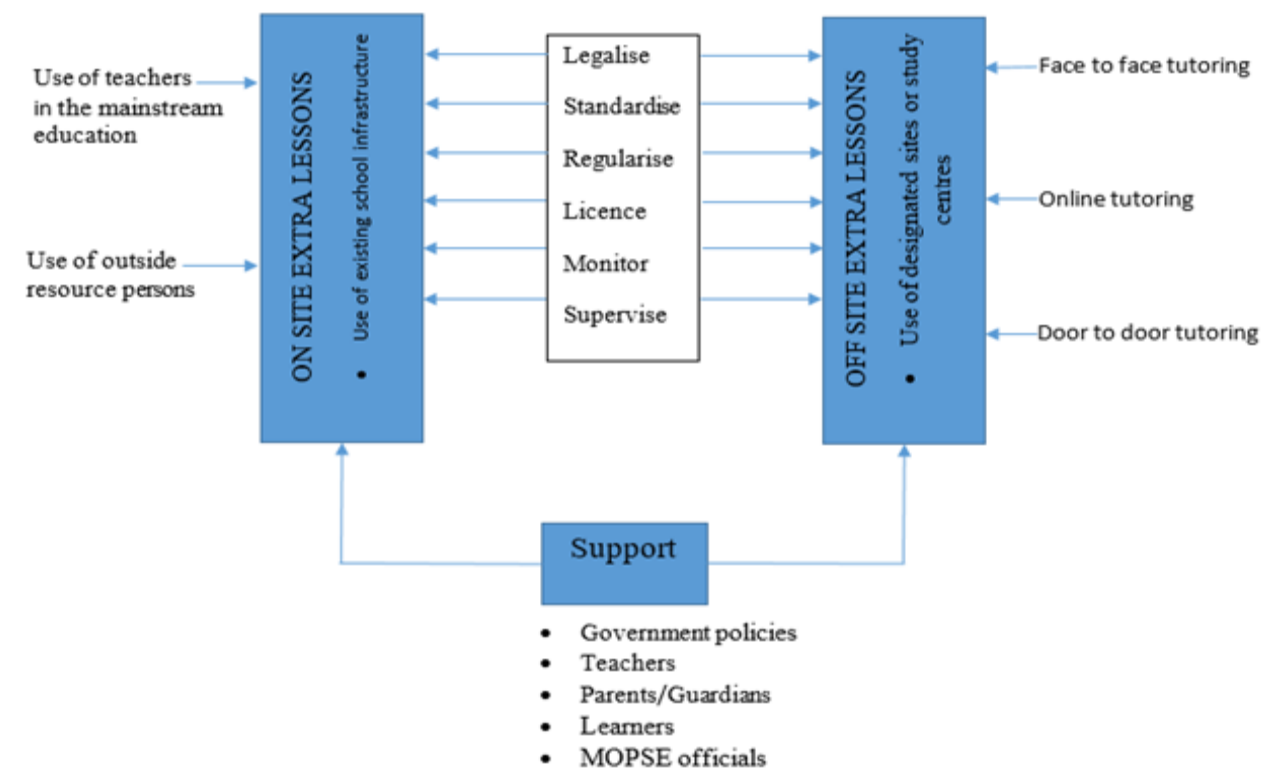

Figure1. The ON-OFF Model of Extra Lessons Implementation 


\section{Elements OF The Model}

The ON-OFF model of extra lessons implementation comprises the onsite and off-site extra lessons, both of which need support through and from government policies, teachers, parents and guardians, learners and MOPSE officials who include the district school inspectors and Provincial Education Directors. On-site extra lessons are those that could be held in the school premises using existing school infrastructure and resources. This incorporates the use of teachers who are already in the mainstream system though they may not necessarily be the ones teaching at the school or the learning area. The model advocates for the use of outside resource persons to teach specific areas. The off-site extra lessons are those that should be held outside the school but at designated sites or study centres, created for that purpose. These incorporate face to face and on-line tutoring as well as door to door extra lessons which entail teachers having to go into the homes of those requiring the extra lessons. In both the on-site and off-site extra lessons, there in need for legalisation, standardisation, regularisation licensing, monitoring and supervision of extra lessons. These aspects are presented below:

\section{Legalising extra lessons}

According to the model, legalising extra lessons is one strategy which could see all stakeholders benefitting from the undertaking. The onus rests with MOPSE to make sure that the legalisation of the practice is effectuated. The legal framework could take on board only those with the appropriate qualifications, as teachers, to offer extra lessons and make the practice legal.

\section{Standardising of the practice of extra lessons}

The model provides for the standardisation of the practice of extra lessons. This calls for the need for uniformity as currently, there is lack of uniformity in the operations of the service providers. Results showed that teachers, for example, charged whatever amount they deemed appropriate, even demanding payment in kind. This, therefore, is also the focus of the model, to make sure where charges are stipulated, these become blanket charges for all service providers.

\section{Regularising the practice}

The model advocates for the MOPSE to make extra lessons as an officially acceptable practice, as currently, there is a tendency to prosecute those offering the service. However, only qualified teachers should continue to teach extra lessons and registered study centres should provide extra lessons.

\section{License}

Another tenet of the model is that extra lesson service providers should be registered and licensed before they can operate (Bray, 2011). Such a strategy has been used for nurses and other workers in the medical as well as the legal fraternity, in Zimbabwe, who have been afforded the opportunity to operate privately, apart from their normal duties in government hospitals, clinics and elsewhere. Operating licences can be issued and renewed on a yearly basis, based on performance and conformity to stipulated regulations.

\section{Monitoring of the practice}

Monitoring is another component of the model which requires that, where regulations have been put in place, there be need to monitor conformity. The issue of conformity could include the need to abide by the fees charged, as determined by MOPSE and physical conditions under which extra lessons are provided, where these are carried off-site. All these need to be monitored by government, to the satisfaction of all stakeholders. Monitoring also assist in dealing with all underhand and unscrupulous activities deemed illegal.

\section{Supervision of extra lessons}

Another basic tenet of the model is the aspect of supervision. There is need for supervision by officials from MOPSE to make sure that where there are weaknesses in the execution of extra lessons, these are dealt with so that the paying parents are not shortchanged in the process.

\section{Offering extra lessons during formal learning hours}

Another suggested strategy is extra lessons should be offered during formal learning hours where learners are found to be idle especially in the hot sitting schools, such as the urban day high density 
secondary schools. This could be done to protect learners from abuse with the hope and help providing effective monitoring, within the school premises. Also this could be undertaken to allow for more learners to take part (Ventura \& Jang, 2010)

\section{Introduction of on-line tutoring}

On-line tutoring is another important aspect of the model. On-line tutoring could help both urban and rural school learners. Learners who are unable to access qualified teachers in their communities could be assisted. On-line tutoring also minimises contact between teachers and learners, that could result in abuse as teachers would take the opportunity to abuse learners in face to face-to-face extra lessons.

\section{Need for support from all sectors and stakeholders}

An aspect that cuts across the model is the need for support from all the stakeholders, who include teachers, MOPSE, parents and learners. The list would include politicians, some of whom are very much against the extra lessons.

\section{REFERENCES}

[1] Baker, D. P., Akiba, M., Le Tendre, G. K. \& Wiseman, A. W. (2011). Worldwide Shadow Education: Outside-School Learning, Institutional quality of School and Cross-National Mathematics Achievement. Educational Evaluation and Policy Analysis, 23(1), 1-17.

[2] Baker, D.P. \& Le Tendre, G.K. (2015). National Differences, Global Similarities: World Culture and the Future of Schooling. Stanford: Stanford University Press.

[3] Bray, M. (1999). The Shadow Education System: Private Tutoring and Its Implications for Planners. Paris: UNESCO, International Institute for Educational Planning.

[4] Bray, M. (2009). Confronting the shadow education system: What government policy for what private tutoring? Paris: International Institute for Educational Planning (IIEP).

[5] Creswell, J. W. (2012). Research design: Qualitative, quantitative, and mixed methods approaches, $\left(2^{\text {nd }}\right.$ ed.). Thousand Oaks, CA: Sage Publications.

[6] Dang, H. \& Rogers, F. H. (2008). The Growing Phenomenon of Private Tutoring: Does it Deepen Human Capital, Widen Inequalities, or Waste of Resources? The World Bank Research Observer, 23(2), 262-200.

[7] Davies, S., \& Aurini, J. (2016). The Franchising of Private Tutoring: A View from Canada. The Phi Del ta Kappan, 88(2), 123-128.

[8] Flick, U. (2011). Introduction to qualitative research. Los Angeles: Sage Publications.

[9] Foondun, A. R. (2012). The Issue of Private Tuition: An Analysis of the Practice in Mauritius and Selected South Asian Countries. International Review of Education, 48(6), 485- 515

[10] Hartman, S. (2008). "At School We Don't Pay Attention Anyway"- The Informal Market of Education in Egypt and Its Implications. Sociologies, 58(1), 27-48.

[11] Hussein, M. G. A. (2007). Private Tutoring: A Hidden Educational Problem. Educational Studies in Mathematics, 18(1), 91-96.

[12] Jinga, N. \& Ganga, E. (2012). Effects of Holiday Lessons and Financial Pressures on Low - Income Families and Households in Masvingo, Zimbabwe Journal of Emerging Trends in Educational Research and Policy Studies (JETERAPS), 2(6), 465-470

[13] Kim, K. M. \& Park, D. (2012). "Impacts of Urban Economic Factors on Private Tutoring Industry." Asia Pacific Education Review, 13(2), 273-280.

[14] Lee, S \& Shouse, R.C. (2011). The Impact of Prestige Orientation on Shadow Education in South Korea. Sociology of Education, 84(3), 212-224.

[15] Munikwa, S. and Mutungwe, E. (2011). Exploring the Practice of "Extra" Lessons as Offered in Chinhoyi Urban Secondary Schools, Mashonaland West Province, Zimbabwe. Journal of Innovative Research in Management and Humanities 2(1), 26-35

[16] Murawska, B. \& Putkiewicz, E. (2006). Supplementary Tutoring in Poland, In Iveta et al. (2011).

[17] Patton, M. Q. (2014). Qualitative research \& evaluation methods: Integrative theory and practice. SAGE Publications.

[18] Postlethwaite, T. N. (2000). Reviewed Work(s): The Shadow Education System: Private Tut oring and Its Implications for Planners by Mark Bray. New York: Taylor \& Francis, Ltd.

[19] Sacmeq (2010). How widespread is the provision of paid tuition in school subjects? SACMEQ Policy Issues Series, Number 7, September 2010. 
[20] Smyth, E. (2009). "Buying Your Way into College? Private Tuition and the Transition to Higher Education in Ireland." Oxford Review of Education 35(7), 1-22.

[21] Ventura, A. \& Jang, S. (2010). Private tutoring through internet: Globalisation and off-showing. Asian Pacific Education Review, 11(10), 59-68.

[22] Zimbabwe Government (2014). Secretary's Circular Minute 1 of 2014: The Vacation School Cancellation dated 2 January 2014. Harare: Ministry of Primary and Secondary Education.

[23] Zimbabwe Government (2014). Secretary's Circular Minute 12 of 2014: Lessons Durings School Holidays dated 18 July 2014. Harare: Ministry of Primary and Secondary Education.

\section{AUTHOR's BIOGRAPHY}

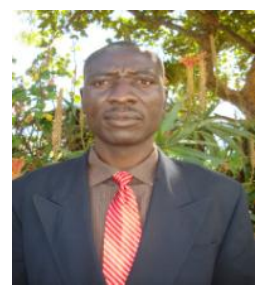

Richard BUKALIYA, is an Associate Professor teaching at the Zimbabwe Open University in the Faculty ofEducation. He is the Regional Programme Coordinator, Mashonaland East Regional Campus, Department of Teacher DevelopmentHe holds aDoctor of Philosophy degree in Educational Management, Master`s Degree in Educational Administration, Planning and Policy Studies (ZOU), Bachelor of Education in Educational Administration, Planning and Policy Studies (UZ), Certificate of Education (UZ), Diploma in Personnel Management (IPMZ)Higher Diploma in Human Resources Management (IPMZ), Certificate in English as a Second Language and a Certificate in Module Writing (ZOU). His research interests include issues in Distance Education and Primary and Secondary education. He has, to date,published extensivelyin several international journals and has one book to his name.

Citation: Richard Bukaliya, Florence Jura. "Stakeholder Perceptions of Intervention Strategies to Improve the Practice of Extra Lessons in Zimbabwean Urban Day High Density Secondary Schools" International Journal of Humanities Social Sciences and Education (IJHSSE), vol 8, no. 4, 2021, pp. 52-62. doi: https://doi.org/10.20431/2349-0381.0804007.

Copyright: (C) 2021 Authors. This is an open-access article distributed under the terms of the Creative Commons Attribution License, which permits unrestricted use, distribution, and reproduction in any medium, provided the original author and source are credited. 